\title{
PENERAPAN METODE BERMAIN SEBAGAI STIMULASI UNTUK MENINGKATKAN PERKEMBANGAN ANAK
}

\author{
Catur Yulinawati $^{1 *}$, Djauhar Ismail $^{2}$, Ekawaty Lutfia Haksari $^{2,}$ Dewi Rokhanawaty ${ }^{1}$ \\ ${ }^{1}$ Fakultas Ilmu Kesehatan, Universitas Aisyiyah Yogyakarta, Jalan Ringroad Barat No.63, Mlangi Nogotirto, Kec. \\ Gamping, Kabupaten Sleman, Daerah Istimewa Yogyakarta, Indonesia 55592 \\ ${ }^{2}$ Fakultas Kedokteran, Kesehatan Masyarakat dan Keperawatan,Universitas Gadjah Mada, J1. Farmako, Senolowo, \\ Sekip Utara, Kec. Depok, Kabupaten Sleman, Daerah Istimewa Yogyakarta, Indonesia 55281 \\ *catur.yulinawati@gmail.com
}

\begin{abstract}
ABSTRAK
Anak usia dini merupakan masa-masa kritis bagi perkembangan nya sebagaimana terjadi pesatnya perkembangan otak sebagai dasar dari pembangunan keterampilan dan kecerdasan berkelanjutan untuk masa depan anak yang terjadi sebelum usia 6 tahun yang dipengaruhi oleh rangsangan dan pengasuhan. Perkembangan anak yang tumbuh di negara berpenghasilan menengah dan rendah gagal mencapai potensi perkembangan, faktor penyebab diantaranya terdapat kemiskinan, kekurangan gizi dan stimulasi yang tidak memadai yang beresiko meningkatkan kematian dan morbiditas. Stimulasi yang dilakukan sesuai dengan tahap belajar anak dengan menerapkan stimulasi dengan metode bermain yang menyenangkan sehingga tujuan peningkatan perkembangan tercapai. Tujuan dari penelitian ini untuk melakukan review pengaruh stimulasi dengan cara bermain terhadap perkembangan pada anak. Sumber data mereview artikel didapatkan dari Pubmed, ProQuest dan Wiley dengan total 390 artikel. adapun artikel yang berhasil di review terdapat 3 artikel sesuai dengan Kriteria inklusi 1) Anak, 2) Bermain, 3) Stimulasi, 4) Perkembangan. Studi appraisal dengan menggunakan Critical Appraisal Skills Program (CASP), metode sintesis dengan menggunakan Patient Intervention Comparison Outcome (PICO). Hasil dari review 3 artikel ini adalah pentingnya melakukan stimulasi dengan bermain seperti menggambar, bermain bola, bernyanyi, tebak kata sangat berpengaruh untuk meningkatkan perkembangan serta memperkuat landasan dalam melakukan penelitian.
\end{abstract}

Kata kunci: anak, bermain, perkembangan, stimulasi

\section{METHOD METHOD OF APPLICATION PLAY AS STIMULATION TO IMPROVE CHILDREN'S DEVELOPMENT}

\begin{abstract}
Early childhood is a critical period for development as rapid brain development occurs as a basis for the development of skills and intelligence for the future of children that occur before the age of 6 years, which is influenced by stimulation and care. The development of children who grow up in middle and low income countries fails to achieve development potential, the contributing factors include poverty, malnutrition and inadequate stimulation that is at risk of increasing death and morbidity. Stimulation is carried out in accordance with the learning stages of children by applying stimulation with play methods that are fun so that the goal of increasing development is achieved. The purpose of this research is to review the effect of stimulation by playing on development in children. Data Sources and Methods : The data source for reviewing articles was obtained from Pubmed, ProQuest and Wiley with a total 390 articles. There are articles successful in reviews there are 3 articles according to the Inclusion criteria 1) Children, 2) Playing, 3) Stimulation, 4) Development. Appraisal study using the Critical Appraisal Skills Program (CASP), synthesis method using Patient Intervention Comparison Outcome (PICO). The results of the review of these 3 articles are the importance of stimulation by playing such as drawing, playing ball, singing, guessing words very influential to improve development and strengthen the foundation in conducting research.
\end{abstract}

Keywords: child, development, play, stimulation

\section{PENDAHULUAN}

Lebih dari 250 juta atau $43 \%$ anak usia dibawah 5 tahun di negara yang berpenghasilan rendah bahkan menengah gagal mencapai potensi perkembangan (Black, M. M., Walker, S.P., 2017; WHO, 2016). Kemiskinan, pengasuhan dan perawatan yang tidak memadai, kurangnya stimulasi dalam pengasuhan memperburuk 
pertumbuhan yang berdampak pada gangguan perkembangan (Black et al., 2013; Blumberg, 2013; Grantham-Mcgregor et al., 2014). Masalah perkembangan dan perilaku pada anak dalam kegiatan sehari-hari sering ditemukan. Di Amerika terdapat $12 \%-16 \%$ anak yang mengalami gangguan tersebut. Karakteristik perkembangan menentukan aspek-aspek yang sama penting nya dengan kesehatan dan kesejahteraan serta kemampuan belajar pada khususnya sehingga diperlukannya stimulasi penting untuk meningkatkan perkembangan pada anak melalui bermain. Anak belajar melalui kegiatan bermain untuk mempercepat perkembangan anak yaitu perkembangan sosial, kognitif, motorik dan linguistik. Oleh karena itu, fakta yang membuktikan bahwa anak berkembang dalam lingkungan sehat dan stimulasi yang memadai sesuai dengan tingkat perkembangan nya melalui peningkatan proses belajar untuk mengembangkan berbagai keterampilan sosial dan akademik (Eberle, 2011; Fisher et al., 2012).

Diperlukan diagnosis sejak dini serta kunjungan ke layanan kesehatan guna deteksi resiko terjadinya penyimpangan yang terjadi pada perkembangan anak dengan penilaian perkembangan sesuai tahapan anak (Blumberg et al., 2019; Zablotsky et al., 2019). Melakukan stimulasi pada anak usia dini sebaiknya dilakukan lebih lama dan memiliki kurikulum yang terstruktur sehingga memungkinkan orang tua an anak-anak berpartisipasi bersama dalam melakukan stimulasi dan menerima umpan balik sesuai harapan (Engle et al., 2011). Pentingnya penelitian ini dilakukan untuk melakukan pengasuhan dan stimulasi yang dilakukan oleh keluarga sendiri dengan cara yang menyenangkan dengan metode bermain sehingga mampu mengatasi kegagalan mencapai perkembangan anak diusia kritis. Tujuan dari kajian literature review ini untuk mengetahui stimulasi perkembangan anak melalui kegiatan bermain pada anak berbasis penelitian-penelitian yang pernah dilakukan untuk memperkuat dalam upaya meningkatkan perkembangan pada anak.

\section{METODE}

Metode yang digunakan dalam penelitian ini adalah systematic review. Research Question yang digunakan untuk melakukan ekstraksi literatur menggunakan metode sintesis modifikasi PICO ; Patient; Balita, Intervention; Stimulasi dengan bermain, Comparison -,Outcome; peningkatan perkembangan. Analisis artikel/penelitian dengan desain studi appraisal: Studi apprasial menggunakan Critical Appraisal
Skills Program (CASP) untuk memeriksa sebuah artikel secara sistematis untuk menilai keabsahan dan relevansinya, instrumen Critical Appraisal Skills Program (CASP) checklist for Systematic Literature dengan melakukan screening melalui 10 pertanyaan. Metode dalam pencarian literature pada studi ini diambil sejak tahun 2008 sampai tahun 2018 pencarian database dengan scanning, dan screening artikel dilakukan secara mandiri. Metode pencarian artikel dengan menggunakan keywords Stimulation OR Stimultan AND Development OR Development Stimulation OR Development abilities AND Play OR Educational Media AND Toddller OR Child. Pencarian literatur dengan 3 database yaitu : Pubmed, Proquest dan Wiley.

Terdapat 3 artikel dari 3 database di identifikasi, screening dengan mengeluarkan artikel yang tidak sesuai kriteria dari judul, abstrak, anonim, tidak berbahasa Inggris dan metode penelitian yang digunakan terdapat 332 artikel, Eligibity adalah artikel teks lengkap yang dinilai sesuai kelayakan dan tidak memenuhi kriteria inklusi terdapat 35 artikel dan included adalah artikel yang memenuhi kriteria inklusi,artikel teks lengkap berdasarkan critical apraissal dan direview terdapat 3 artikel berdasarkan kriteria inklusi dan eksklusi yaitu: 1) Anak, 2) Bermain, 3) Stimulasi, 4) Perkembangan 3) Full text, Artikel tahun 2008-2018, jurnal Internasional untuk dilakukan critical appraisal untuk di review.

\section{HASIL}

Stimulasi Tumbuh dan Kembang pada Balita meliputi stimulasi perkembangan kognitif, perkembangan motorik, dan bahasa.

Stimulasi Kognitif : Penelitian (Muhoozi et al., 2018) tentang Nutrisi, Kebersihan, dan pendidikan stimulasi untuk meningkatkan pertumbuhan, kognitif, bahasa, dan perkembangan motorik pada bayi di Uganda, Cluster Randomized Trial. Dari jumlah total sampel sebanyak 512 balita, di bagi menjadi 2 kelompok yaitu; kelompok kontrol di bagi menjadi 224 balita sedangkan kelompok intervensi menjadi 243 balita, terjadinya pengurangan sampel akibat dari adanya kelainan bawaan (cerebral palsy, hydrosefalus dan gangguan perkembangan lainnya), ada yang meninggal dan hilang. Perkembangan kognitif di lakukan dengan penilaian Bayley Scale of Infant Development pengukuran standar perkembangan balita, dengan $p$ value 0001 yang artinya terdapat kenaikan yang signifikan pada kelompok intervensi. Penting nya bermain kognitif, bahasa, dan perkembangan motorik balita bersama-sama 
dengan ibu dengan kegiatan bermain yang spesifik dan mainan yang berguna dalam mengembangkan setiap domain yang didasarkan pada sosial, teori belajar kognitif, dimana ibu diajarkan manfaat dari praktek stimulasi.

Tim pendidik bersama sama dengan para ibu menyelesaikan cara menstimulasi dan rintangan untuk melakukan intervensi pada stimulasi. Perkembangan kognitif di berikan stimulasi dengan mengenal nama-nama benda dan mampu mengidentifikasi bagian-bagian dari tubuh, kemudian bermain petak umpet, mampu memberikan makan pada boneka jika di berikan cangkir dan sendok. Stimulasi perkembangan pada balita dengan menggunakan 5 permainan sederhana, ibu di berikan petunjuk tentang cara menggunakannya untuk ikut terlibat dan bermain dengan balita mereka. Dan diperkuat dengan penelitian (Vazir et al., 2014) dengan hasil untuk kelompok intervensi yang mendapatkan pendidikan nutrisi dan stimulasi dengan permainan sederhana dapat di analisis bahwa skor perkembangan secara signifikan lebih tinggi disusul oleh kelompok intervensi pendidikan nutrisi/gizi dan pemberian makanan tambahan di banding kelompok kontrol. Tetapi perbedaan ini secara statistik tidak signifikan. Hasil penelitian (Yousafzai et al., 2014) 1391 dari 1489 (93\%) ibu - ibu yang mengikuti penelitian ini hingga selesai, adapun $P$ value $<0.0001$ pada perkembangan kognitif yang artinya adanya kemaknaan terkait perkembangan kognitif pada balita.

Stimulasi Motorik : Penelitian (Yousafzai et al., 2014) untuk perkembangan motorik balita $P$ < 0.0001 dapat disimpulkan kenaikan perkembangan motorik mempunyai kemaknaan dengan perkembangan. Dari 1489 ibu - ibu dari balita yang terdaftar, $93 \%$ telah mengikuti tahap tahap stimulasi dengan baik, balita menerima stimulasi yang memiliki skor secara signifikan lebih tinggi pada pengembangan motorik, kognitif dan bahasa dibandingkan pada kelompok kontrol yang tidak mendapatkan intervensi. Stimulasi responsive pada peningkatan motorik dengan skala penilaian $0-5$. Sama halnya dengan penelitian yang di lakukan oleh (Muhoozi et al., 2018) kelompok intervensi telah mendapatkan penilaian lebih tinggi pada penilaian perkembangan, yakni pada perkembangan motorik 95\% CI $(10.9,18,2), \mathrm{p}=0.0001$ yang artinya terdapat peningkatan signifikan. Ada peningkatan yang signifikan dalam skor kognitif dan motorik yang di ukur menggunakan BSID III (Bayley Scale of Infant Development III) dan (Vazir et al., 2014). Dan skor psikomotor index lebih tinggi pada kelompok intervensi yang mendapatkan pendidikan nutrisi dan stimulasi dengan permainan sederhana. Stimulasi motorik dilakukan dengan pengendalian gerak tubuh dilakukan seperti melakukan koordinasi antara otak, otot dan susunan syaraf seperti mengambil barang-barang dengan cara menjumput, mencoret coret, cara memegang pensil, melempar bola, menendang bola, merangkak, dan berjalan.

Stimulasi Bahasa : Perkembangan bahasa, tim melakukan penekanan untuk bermain peran, bermain game, menyayikan sebuah lagu dan bermain musik. Ibu di dorong untuk sering melakukan komunikasi lebih aktif dan sering mengenalkan nama-nama suatu benda, nama hewan, barang-barang pribadi dalam kegiatan sehari-hari dengan gaya meniru atau melakukan tindakan. Penelitian yang dilakukan oleh (Yousafzai et al., 2014) balita yang menerima intervensi memiliki nilai yang signifikan lebih tinggi pada pengembangan bahasa pada usia 12 bulan sampai dengan 24 bulan. Dan skor tertingi adalah bahasa dengan skala penilaian 0-7 dibandingkan yang di susul oleh kognitif dan perkembangan motorik. $P$ value $<0.0001$ setelah dilakukan intervensi dengan melatih balita bernyanyi, mendegarkan lagu dan sebagainya. Hal ini di perkuat dengan penelitian (Muhoozi et al., 2016) sebagian besar (84\%) ibu dari balita-balita yang di lakukan intervensi telah mengikuti tahapan stimulasi dengan baik perbedaan rata rata pada peningkatan perkembangan bahasa yaitu $9,9,95 \%$ CI $6,4,13,2)$ dengan $p$ value 0.0001 dan(Vazir et al., 2014) dalam penelitiannya tidak meneliti dan membahas mengenai peningkatan perkembangan pada bahasa.

\section{PEMBAHASAN}

Stimulasi Tumbuh dan Kembang pada Balita meliputi stimulasi perkembangan kognitif, perkembangan motorik, dan bahasa.

Stimulasi Kognitif : Hasil pengkajian yang di lakukan terhadap ke tiga jurnal tersebut dapat disimpulkan bahwa stimulasi kognitif sangat penting dan kaitannya dengan faktor pendukung untuk perkembangan balita. (Yousafzai et al., 2014) intervensi perkembangan balita dini terintegrasi dengan pendidikan ibu atau pengasuh saat melakukan permainan, hasil menunjukkan bahwa intervensi stimulasi responsive memiliki maanfaat yang signifikan pada kognitif balita. Hasil penelitian (Vazir et al., 2014) kemungkinan bahwa pesan pada stimulasi melalui peningkatan bermain antara bayi dan ibu atau pengasuh dapat memberikan motivasi dan aspirasi dalam prestasi 
sekolah pada masa depan balita. Dalam melakukan permainan, ibu atau pengasuh hendaknya mengerti bagaimana melakukan stimulasi dengan permainan tersebut, kegiatan ini membantu balita-balita untuk belajar lebih terampil yang berguna dan bermanfaat pada prestasi sekolah melalui 5 permainan sederhana (Muhoozi et al., 2018).

Kegiatan bermain yang spesifik dan mainan yang dapat berguna dalam menggembangkan setiap domain pembangunan. Para ibu didorong untuk terlibat dalam kegiatan bermain. Intervensi stimulasi di dasar kan pada sosial, teori belajar kognitif, di mana ibu diajarkan manfaat dari praktek stimulasi. Stimulasi kognitif tidak hanya di kaitkan dengan pemberian mainan sederhana saja tetapi untuk mendukung hal tersebut, perkembangan kognitif berkorelasi positif dan signifikan dengan hampir semua indikator status gizi (Muhoozi et al., 2016).

Dua tahun pertama kehidupan sering di lambangkan "jendela kritis" untuk pertumbuhan dan perkembangan kognitif dan sosial (Victora et al., 2008). Meningkatkan kualitas interaksi ibu dan balita melalui intervensi pendidikan telah di tunjukan dalam beberapa studi untuk meningkatkan perkembangan kognitif baik di negara berpenghasilan tinggi dan rendah dan menengah (Walker et al., 2011).

Stimulasi Motorik : Hasil dalam review ketiga jurnal koordinasi antar otak, susunan syaraf pusat dan otot sangat berkesinambungan. Motorik halus seperti memegang pensil, menggunting kertas, melipat kertas dan lain sebagainya, adapun motorik kasar seperti permainan yang berinteraksi dengan anggota tubuh seperti bertepuk tangan, merangkak, berjalan, menendang bola dan sebagainya. Studi sebelumnya, telah menunjukkan kontribusi positif yang sangat signifikan bahwa gender dapat memprediksi perkembangan kognitif dan motorik pada balita.

(Yousafzai et al., 2014) hasil pembangunan menunjukkan bahwa di bandingkan dengan balita yang tidak menerima stimulasi responsive, balita terkena rangsangan responsive memiliki peningkatan yang sangat signifikan lebih tinggi pada perkembangan kognitif, bahasa dan motorik yang tidak dapat di pisahkan. (Ahun et al., 2017; Van De Bongardt et al., 2014; Vazir et al., 2014) dan penilaian yang dilakukan untuk menilai perkembangan pada motorik balita dapat dilakukan dengan Bayley Scale of Infant
Development merupakan pengukuran standar perkembangan bayi dan balita.

Bahasa : (Muhoozi et al., 2018) dan (Vazir et al., 2014) menyatakan kegiatan stimulasi bahasa sederhana untuk balita termasuk bicara, menyanyi dan bercerita, dan kemudian membaca untuk balita sangat penting dilakukan, diantara kesibukan orang tua, keluarga maupun pengasuh. Dengan mempunyai kesibukan yang berat, seluruh anggota keluarga dapat meluangkan waktu yang cukup untuk melatih melibatkan anak untuk melakukan stimulasi bahasa.

Hasil dari keseluruhan penelitian dapat di jelaskan dan di perkuat ada beberapa upaya yang dapat dilakukan untuk meningkatkan bahasa balita dengan keterlibatan orang tua, keluarga maupun orang-orang terdekat yang tinggal di rumah mereka. Misalnya dengan membaca buku cerita, bercerita, dan dapat dengan menyanyikan lagulagu, hasil temuan hanya $7.1 \%$ dari total balita yang mempunyai buku yang dapat menstimulasi perkembangan balita terutama bahasa. Hal ini sejalan dengan penelitian yang dilakukan dengan rangkaian yang sama (Cromwell et al., 2014; Rademeyer, V. K. M., Jacklin, L., \&Maxeke, 2013; Singla et al., 2015) Stimulasi bahasa sangat penting di lakukan oleh ibu, bapak, kakak, pengasuh maupun anggota keluarga lain seperti bernyanyi, membaca dengan bercerita, komunikasi dan di dukung oleh media lain seperti buku cerita dan video bernyanyi.

\section{SIMPULAN}

Penelusuran dan literature review terhadap 3 jurnal perkembangan anak adalah pentingnya melakukan stimulasi dengan penerapan metode bermain pada anak sesuai tahapan perkembangannya. Stimulasi perkembangan kognitif, motorik dan bahasa dilakukan dengan bermain sederhana yang dapat dilakukan dirumah dalam kegiatan sehari-hari yang digunakan sebagai landasan mencapai potensi perkembangan serta dalam melakukan penelitian perkembangan pada anak.

\section{DAFTAR PUSTAKA}

Ahun, M. N., Geoffroy, M. C., Herba, C. M., Brendgen, M., Séguin, J. R., Sutter-Dallay, A. L., Boivin, M., Tremblay, R. E., \& Côté, S. M. (2017). Timing and Chronicity of Maternal Depression Symptoms and Children's Verbal Abilities. Journal of Pediatrics, $\quad 190, \quad 251-$ 257.https://doi.org/10.1016/j.jpeds.2017.07. 
007

Black, M. M., Walker, S.P. (2017). Easy Childhood Development Coming of Age,. https://doi.org/DOI : 10.17226/24737

Black, R. E., Victora, C. G., Walker, S. P., Bhutta, Z. A., Christian, P., De Onis, M., Ezzati, M., Grantham-Mcgregor, S., Katz, J., Martorell, R., \& Uauy, R. (2013). Maternal and child undernutrition and overweight in low-income and middle-income countries. The Lancet, 382(9890), 427-451. https://doi.org/10.1016/S01406736(13)60937-X

Blumberg. (2013). ntroduction: Digital Games as a Context for Cognitive Development, Learning, and Developmental Research. 2013(139),1-9.

https://doi.org/https://doi.org/10.1002/cad.2 0026

Blumberg, F. C., Deater-Deckard, K., Calvert, S. L., Flynn, R. M., Green, C. S., Arnold, D., \& Brooks, P. J. (2019). Digital Games as a Context for Children's Cognitive Development:Research Recommendations and Policy Considerations. Social Policy Report,32(1),1-33.

https://doi.org/10.1002/sop2.3

Cromwell, E. A., Dube, Q., Cole, S. R., Chirambo, C., Dow, A. E., Heyderman, R. S., \& Van Rie, A. (2014). Validity of US norms for the Bayley Scales of Infant Development-III in Malawian children. European Journal of Paediatric Neurology,18(2),223-230.

https://doi.org/10.1016/j.ejpn.2013.11.011

Eberle, S. G. (2011). Playing with the Multiple Intelligences: How Play Helps Them Grow. American Journal of Play, 4(1), 19-51.

Engle, P. L., Fernald, L. C. H., Alderman, H., Behrman, J., O'Gara, C., Yousafzai, A., De Mello, M. C., Hidrobo, M., Ulkuer, N., Ertem, I., \& Iltus, S. (2011). Strategies for reducing inequalities and improving developmental outcomes for young children in low-income and middle-income countries. The Lancet, 378(9799), 1339$1353 . \quad$ https://doi.org/10.1016/S01406736(11)60889-1

Fisher, K., Hirsh-Pasek, K., Golinkoff, R. M.,
Singer, D. G., \& Berk, L. (2012). Playing Around in School: Implications for Learning and Educational Policy. In The Oxford Handbook of the Development of Play (Issue August 2018). https://doi.org/10.1093/oxfordhb/97801953 93002.013.0025

Grantham-Mcgregor, S. M., Fernald, L. C. H., Kagawa, R. M. C., \& Walker, S. (2014). Effects of integrated child development and nutrition interventions on child development and nutritional status. Annals of the New York Academy of Sciences, 1308(1), 11-32. https://doi.org/10.1111/nyas.12284

Muhoozi, G. K. M., Atukunda, P., Diep, L. M., Mwadime, R., Kaaya, A. N., Skaare, A. B., Willumsen, T., Westerberg, A. C., \& Iversen, P. O. (2018). Nutrition, hygiene, and stimulation education to improve growth, cognitive, language, and motor development among infants in Uganda: A cluster-randomized trial. Maternal and Child Nutrition, 14(2), 1-11. https://doi.org/10.1111/mcn.12527

Muhoozi, G. K. M., Atukunda, P., Mwadime, R., Iversen, P. O., \& Westerberg, A. C. (2016). food \& nutrition. 1, 1-11.

Rademeyer, V. K. M., Jacklin, L., \&Maxeke, C. (2013). A study to evaluate the performance of black South African urban infants on the Bayley Scales of Infant Development III. South African Journal of Child Health, 7, 54-59, $\mathrm{Vol} 7, \mathrm{No}$.

Singla, D. R., Kumbakumba, E., \& Aboud, F. E. (2015). Effects of a parenting intervention to address maternal psychological wellbeing and child development and growth in rural Uganda: A communitybased, cluster-randomised trial. The Lancet Global Health, 3(8), e458-e469. https://doi.org/10.1016/S2214109X(15)00099-6

Van De Bongardt, D., De Graaf, H., Reitz, E., \& Deković, M. (2014). Parents as moderators of longitudinal associations between sexual peer norms and Dutch adolescents' sexual initiation and intention. Journal of Adolescent Health, 55(3), 388-393. https://doi.org/10.1016/j.jadohealth.2014.02 .017 
Vazir, S., Engle, P., Balakrhisna, N., Griffiths, P. L., Jhonson, S. L., Creed-Kanashiro, H. M., Rao, S. F., Shroff, M. R., \& Bentley, M. E. (2014). feeding education to caregivers found improved dietary intake, growth, and development among rural Indian toddlers. Matern Child Nutr, 9(1), 99-117. https://doi.org/10.1111/j.1740-

8709.2012.00413.x.Cluster-randomized

Victora, C. G., Adair, L., Fall, C., Hallal, P. C., Martorell, R., Richter, L., \& Sachdev, H. S. (2008). Maternal and child undernutrition: consequences for adult health and human capital. The Lancet, 371(9609), 340-357. https://doi.org/10.1016/S01406736(07)61692-4

Walker, S. P., Chang, S. M., Vera-Hernández, M., \& Grantham-McGregor, S. (2011). Early childhood stimulation benefits adult competence and reduces violent behavior. Pediatrics, 127(5), 849-857. https://doi.org/10.1542/peds.2010-2231

WHO. (2016). Early Child Development, World Health Organization.

Yousafzai, A. K., Rasheed, M. A., Rizvi, A., Armstrong, R., \& Bhutta, Z. A. (2014). Effect of integrated responsive stimulation and nutrition interventions in the Lady Health Worker programme in Pakistan on child development, growth, and health outcomes: A cluster-randomised factorial effectiveness trial. The Lancet, 384(9950), 1282-1293. https://doi.org/10.1016/S01406736(14)60455-4

Zablotsky, B., Black, L. I., Maenner, M. J., Schieve, L. A., Danielson, M. L., Bitsko, R. H., Blumberg, S. J., Kogan, M. D., \&
Boyle, C. A. (2019). Prevalence and trends of developmental disabilities among children in the United States: 2009-2017. Pediatrics, 144(4), 2009-2017. https://doi.org/10.1542/peds.2019-0811 